\title{
Analysis on the Development Problems of Xi'an Cultural Tourism Products under the New Situation
}

\author{
Xiaoqing Zhu \\ Xi'an University, Xi’an, Shaanxi, 710065
}

Keywords: New Situation; Xi'an; Cultural Tourism; Product Development; Problems

\begin{abstract}
Based on the current situation of tourism development in Xi'an in the new situation as the main research background, this paper takes the product development in the cultural tourism industry as the main content and combines with the perspective of the development of the Silk Road Economic Belt in order to promote the cultural tourism industry. The development of product puts forward the corresponding key strategies to better promote the development of cultural tourism industry in Xi'an and fundamentally, promotes the process of economic development in Shaanxi Province.
\end{abstract}

\section{Introduction}

To some extent, the cultural characteristics and cultural details of a certain area are the intrinsic motivation to promote the prosperous development of tourism in this area. It can be said that tourism is an important carrier and an important manifestation of heritage culture and has great development significance. According to many years of practice, tourism and culture have innate integration and dependence, and they develop together and depend on each other. For example, tourism can greatly increase the cultural heritage and vitality. However, a culture with vitality and heritage can appropriately increase the popularity and attractiveness of tourist destinations. The article discusses the Xi'an itself has a larger cultural heritage, many countries are unearthed cultural relics in this place, such as Terracotta Warriors and Horses, known as "one of the world's eight wonders," there have been more than 200 foreign leaders Visit, with greater heritage value. Therefore, it is necessary for us to explore and study the development of cultural tourism products in Xi'an.

\section{Current Situation of Xi'an Cultural Tourism Industry Development}

As one of the major leading undertakings in Shaanxi, tourism plays an effective role in promoting economic development in Shaanxi Province. To a certain extent, the development of tourism and cultural industries has a direct impact on the economic development of Shaanxi Province. The tourism industry in Shaanxi Province, led by Xi'an, has great tourism value at this stage mainly because Xi'an has unearthed a large number of relics of historical value such as the Terracotta Warriors and Horses of Xi'an and became the mainstay of tourism in Shaanxi Province. From a cultural point of view, cultural resources in Xi'an have more prominent features, such as the history and culture of the Qin Dynasty, the Han Dynasty and the Tang Dynasty quite abundant; Guanzhong folk culture has the distinct characteristics; influenced by the revolutionary culture in northern Shaanxi, The rich cultural resources [1]. In addition to the above points, Xi'an is also the fundamental base of our country's modern education and culture. It is rich in cultural heritage and conducive to carrying forward our country's traditional culture. In terms of the overall composition of cultural resources in Shaanxi Province, we can subdivide Shaanxi's cultural resources into the Chinese clan culture, imperial culture, artistic culture and traditional Buddhist Taoism culture. In addition, there are landscape culture represented by Zhongnanshan, Guanzhong food culture and other aspects of national culture, Shaanxi Province can be drawn from the rich cultural resources, thus giving Xi'an more cultural resources.

As the dominant force and important representative of Shaanxi cultural tourism, the coordinated 
development of culture and tourism in Xi'an area has a far-reaching promotion significance for the overall economic development in Xi'an. At this stage, the basic pattern of development of cultural tourism in Xi'an mainly presents the situation of "one belt and three districts", including the ecology of the northern foot of Qinling Mountains, the cultural belt of tourism industry that we often say, the Qujiang National Demonstration and Cultural Tourism Zone, Tourism industry gathering area and Lintong cultural tourism industry gathering area. Among them, the Qujiang National Demonstration and Cultural Tourism Zone, as the development source of the cultural tourism industry in Xi'an, is fully integrated with the cultural features of the Tang Dynasty and makes good use of the existing cultural resources. Based on this, the all-round integration and launch of the Qujiang National Demonstration and Cultural Tourism Zone A lot of development projects, to a great extent effectively highlighted the retro features of the region's culture [2]. In response, the local government actively formed Qujiang Cultural Industry Investment Co., Ltd., Culture and Tourism Group and other large-scale cultural tourism projects. For example, the state-owned cultural undertaking such as the Wild Goose Pagoda Scenic Area actively integrates with local cultural resources and becomes a successful example of the synergistic development of local culture and tourism.

\section{Cultural tourism industry development in the existing product development issues}

In recent years, the cultural tourism in Shaanxi Province, with Xi'an as its leading force, has shown a thriving scene. The overall development situation is flourishing. According to the statistics from China National Tourism Administration, we can see that in the first half of 2015, Shaanxi Province put forward the development measure of "being steady, improving quality and increasing efficiency" under the pressure of the international situation and the domestic economic development situation. The main purpose is to imprison Firmly grasp the economic characteristics of the Silk Road and take its development characteristics as a turning point for new construction to better cater to the development trend of the new normal of economic development.

After the promulgation of this policy, the total tourism revenue in Shaanxi Province has reached double-digit growth, and the corresponding industrial status is also in a state of continuous improvement. In terms of the development of cultural tourism products, Shaanxi Province launched the tourism products of "Red Tourism" and "Mausoleum Culture Tourism" in combination with the characteristics of local cultural resources. On the basis of this, Shaanxi Province introduced Ningqiang Qingmuchuan as the main The representative of the rural tourism brand, to a great extent, play a leading role in tourism products [3]. Compared with other regions in Shaanxi Province, the development of tourism products compared to the obvious lack of more obvious in Xi'an, mainly concentrated in the following areas:

In the actual development of tourism products, ignoring the current hot spots of tourism products or focusing on the immediate interests while neglecting the overall cultural concept can not effectively develop the tourism products of local cultures. At this stage, the development of tourism products in Shanxi still stays on the aspects of scenic spots, scenic spots and tourist development routes. The overall awareness of tourism culture is rather weak. For example, it does not pay enough attention to the deep native culture of Shaanxi Province, Lack of in-depth exploitation and excavation, nor do they detail the shaping of tourism products based on the cultural perspective [4]. No matter from macroscopical or long-term point of view, this kind of product development method obviously insufficient stamina, is not conducive to tourism in Shanxi Province to achieve the goal of prosperity and development. For example, the terracotta warriors of Qin Shihuang belonged to a world-class cultural brand and deserved to be a "living specimen" to show visitors the history and culture of China. However, in fact, the terracotta warriors and horses of the Qin Shihuang just met the visual perception of tourists and did not let the tourists feel the Qin Shihuang Terra cotta Warriors inherent in the historical and cultural characteristics, can not inherit Chinese history and culture, contrary to the original purpose of tourism development.

Combined with the current development trend of cultural tourism in terms of Shanxi, cultural tourism has become a high level, high grade tourism experience activities. People's travel behavior 
from the original pursuit of natural scenery, enjoy leisure and entertainment, and gradually transformed into a high level of cultural taste, the purpose of people to travel more lies in cultivating sentiments, the pursuit of self. However, a series of imitations, patchwork and curiosity have become the main problems in the development of tourism products in Xi'an at present. For example, some tourism projects are not clearly defined in the market and are not very accurate in terms of market targeting, most travel merchants will blindly follow the higher economic benefits they get from a certain tourism project. This directly causes the price war in tourism products, which is what we call disorderly competition.

As a world-class ancient city of cultural tourism, the geographical location of Xi'an does not have obvious advantages. There are not many tourist boutique items that match with it, and the cultural products produced are relatively small, that is to say, it can be combined with the tourism and cultural industries There is almost no cultural quality, can not fundamentally realize the development of mutual benefits and common prosperity. For example, tourist souvenirs produced in Xi'an are mainly imitation products, which are more difficult to meet the needs of modern travelers in terms of color saturation and variety quality. In addition, the lack of pertinence in the development of high value-added and high-tech tourism and cultural products has greatly hindered the development of cultural tourism products in Xi'an and hindered the development and construction of local tourism [5].

\section{The Xi'an cultural tourism industry development opportunities related to the description}

In September 2013, President Xi Jinping visited the relevant meetings of the four Central Asian countries and proposed the important strategy of building the Silk Road Economic Belt at the meeting in Kazakhstan. It has received extensive attention from all over the world. After more than two years of practice and development, the strategic goal of building the Silk Road Economic Belt has greatly changed the tourism patterns in various regions of our country. The cultural tourism destination led by Xi'an is the key to realizing the economic belt of the Silk Road The strategic indicators provide a platform for development. According to Li Parkmin, Secretary-General of the National Development and Reform Commission, at the State Symposium on Building the Silk Road Economic Belt, we can generally understand that the main methods of building the Silk Road Economic Belt can be implemented in seven aspects: First, to promote the interconnection of infrastructure; second, to enhance the level of economic and trade cooperation; third, to expand the channels for industrial investment; fourth, to deepen the cooperation of energy resources; Fifth, to broaden the field of development of financial cooperation; Close cooperation level of humanities and communication; Seventh, strengthen cooperation in ecological environment.

As the starting point for the development of the "ancient Silk Road", Xi'an has more than two thousand years of history of silk culture, which is of great significance for the realization of the economic belt for building the Silk Road. At the same time, Xi'an is also the city with the comparative center of China-Eurasia Continental Bridge at this stage. To a certain extent, Xi'an has obvious geographical advantages and characteristics. Once the Xi'an area and Silk Road Economic Belt fully and effectively combined, as the realization of the Silk Road Economic Belt focus on the development of the region is bound to Xi'an will play an important economic development, such as driving Xi'an Tourism Career development process, which is conducive to the development of tourism and cultural products. To sum up, it is clear that building the Silk Road Economic Belt has an important practical significance for the development of tourism in Xi'an and belongs to the new situation for the development opportunities provided by Xi'an. To this end, we should actively integrate the existing tourism resources in Xi'an, and combine with the actual needs of consumers to continuously enhance the soft power of Xi'an and effectively solve the problems of product development existing in the development of cultural tourism industry in Xi'an [7].

\section{To enhance Xi'an cultural tourism product development level of effective measures}

The main characteristic of tourism products in Xi'an lies in the Han and Tang Dynasties culture 
as the main representative of the culture, which is also the core of Shaanxi tourism and cultural development concepts and advantages. In my opinion, Shaanxi Province should try its best to locate the history and culture in the development of tourism products to reflect the local cultural characteristics, cultural concepts and national culture. In other words, Xi'an should establish all-round historical and cultural tourism related concepts and leadership image, do a good job of specific, distinct cultural orientation, as far as possible in the market monopoly advantages and characteristics, and this advantage and characteristics Fully play out [8]. In the light of the current orientation of cultural image, Xi'an should rationally combine the development of the Silk Road Economic Belt with the cultural characteristics of the Qin culture, the Tang culture and the Han culture, and do a good job of locating cultural images as a basis as the basis for the development of cultural tourism products, all-round promotion of Xi'an cultural tourism product development level.

Relevant scholars believe that the cultural connotation involved in tourism resources needs to cover at least five aspects: science, history, literature, arts and society. Xi'an, as the starting point of the Silk Road, with its rich cultural resources and unique geographical location, has become the main means of implementing the Silk Road Economic Belt. As the ancient civilized capital in the thirteenth dynasty, Xi'an precipitated and accumulated more cultural heritage in history and culture. Based on this advantage, we should always insist on the principle of integrating culture with tourism when exploring tourism products, deeply tap the cultural connotation of the region, and design a tourism product that has both culture and tourism characteristics. Highlight the creativeness of cultural tourism products [9].

\section{Conclusions}

Based on the local tourism economic perspective in Xi'an, relevant personnel should develop and design tourism projects according to the current special culture and set up tourism products that are in line with local cultural characteristics. On the basis of this, we should make full use of the development perspective of Silk Road Economic Belt to advance with the times and add luster to the tourism industry in Xi'an so as to promote the development of tourism in our country fundamentally.

\section{References}

[1] Qi-hua. Silk Road Economic Belt in Xi'an Starting Point Silk Road Cultural Tourism Product Development [D]. Northwestern University, 2016.

[2] Li Jingjing. Based on the cultural experience of the Silk Road Tourism Development Model [D]. Beijing Jiaotong University, 2017.

[3] Tian Ting. Research on the Development of Cultural Tourism Enterprises from the Perspective of Cultural Ecology [D]. Beijing Jiaotong University, 2012.

[4] Yang Yanping, Xing Na, Daosheng Jun. Analysis of Xi'an cultural tourism product development in the new situation [J]. Travel Overview (second half), 2016 (04): 206-207 +209.

[5] Yang Juncheng. Study on the Development of Xi'an Cultural Resources Based on the Tourist Cognitive Perspective [D]. Northwest University, 2007.

[6] Wang Xiaoxi. Xi'an White Deer Tourism Development Strategy Research [D]. Xi'an University of Architecture and Technology, 2012.

[7] Han Ting-ting. Research on Tourism Product Development of Xi'an Wall Based on Experience Design [D]. Xi'an International Studies University, 2017.

[8] Zhang Xin. Research on the Development of Cultural Relics Resources Tourism Products [D]. Chongqing Normal University, 2014.

[9] Xu Xiaobo. Xi'an Qujiang ruins tourism development model [D]. Northwest University, 2011. 